\title{
Multifunctional photo/thermal catalysts for the reduction of carbon dioxide
}

Schwartzenberg, K. C., Hamilton, J., Lucid, A. K., Weitz, E., Notestein, J., Nolan, M., Byrne, JA., \& Gray, K. A. (2017). Multifunctional photo/thermal catalysts for the reduction of carbon dioxide. Catalysis Today, 280(Part 1), 65-73. https://doi.org/10.1016/j.cattod.2016.06.002

Link to publication record in Ulster University Research Portal

\author{
Published in: \\ Catalysis Today
}

Publication Status:

Published (in print/issue): 01/02/2017

DOI:

10.1016/j.cattod.2016.06.002

\section{Document Version}

Author Accepted version

\section{General rights}

Copyright for the publications made accessible via Ulster University's Research Portal is retained by the author(s) and / or other copyright owners and it is a condition of accessing these publications that users recognise and abide by the legal requirements associated with these rights.

\section{Take down policy}

The Research Portal is Ulster University's institutional repository that provides access to Ulster's research outputs. Every effort has been made to ensure that content in the Research Portal does not infringe any person's rights, or applicable UK laws. If you discover content in the Research Portal that you believe breaches copyright or violates any law, please contact pure-support@ulster.ac.uk. 




UCC Library and UCC researchers have made this item openly available. Please let us know how this has helped you. Thanks!

\begin{tabular}{|c|c|}
\hline Title & $\begin{array}{l}\text { Multifunctional photo/thermal catalysts for the reduction of carbon } \\
\text { dioxide }\end{array}$ \\
\hline Author(s) & $\begin{array}{l}\text { Schwartzenberg, K. C.; Hamilton, J. W. J.; Lucid, Aoife K.; Weitz, E.; } \\
\text { Notestein, J.; Nolan, Michael; Byrne, J. Anthony; Gray, K. A. }\end{array}$ \\
\hline Publication date & 2016-06-17 \\
\hline Original citation & $\begin{array}{l}\text { Schwartzenberg, K. C., Hamilton, J. W. J., Lucid, A. K., Weitz, E., } \\
\text { Notestein, J., Nolan, M., Byrne, J. A. and Gray, K. A. (2017) } \\
\text { 'Multifunctional photo/thermal catalysts for the reduction of carbon } \\
\text { dioxide', Catalysis Today, } 280 \text { (Part 1), pp. 65-73. doi: } \\
\text { 10.1016/j.cattod.2016.06.002 }\end{array}$ \\
\hline Type of publication & Article (peer-reviewed) \\
\hline \multirow{2}{*}{$\begin{array}{l}\text { Link to publisher's } \\
\text { version }\end{array}$} & http://www.sciencedirect.com/science/article/pii/S0920586116303923 \\
\hline & $\begin{array}{l}\text { http://dx.doi.org/10.1016/j.cattod.2016.06.002 } \\
\text { Access to the full text of the published version may require a } \\
\text { subscription. }\end{array}$ \\
\hline Rights & $\begin{array}{l}\text { C } 2016 \text { Elsevier B.V. This manuscript version is made available } \\
\text { under the CC BY-NC-ND } 4.0 \text { license. } \\
\text { http://creativecommons.org/licenses/by-nc-nd/4.0/ }\end{array}$ \\
\hline Embargo information & $\begin{array}{l}\text { Access to this article is restricted for } 24 \text { months after publication by } \\
\text { request of the publisher. }\end{array}$ \\
\hline Embargo lift date & 2018-06-17 \\
\hline $\begin{array}{l}\text { Item downloaded } \\
\text { from }\end{array}$ & http://hdl.handle.net/10468/4947 \\
\hline
\end{tabular}

Downloaded on 2019-07-23T09:13:25Z

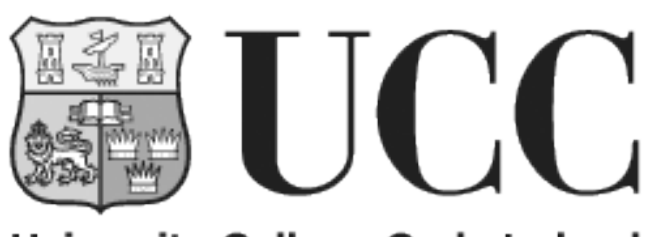




\section{Multifunctional photo/thermal catalysts for the reduction of carbon dioxide}

K.C. Schwartzenberga , J.W.J. Hamilton ${ }^{\text {b }}$ A. K. Lucid ${ }^{\mathrm{c}}$, E. Weitz ${ }^{\mathrm{a}}$, J. Notestein ${ }^{\mathrm{a}}$, M. Nolanc ${ }^{\star}$, J.A. Byrne $\mathrm{b}^{\star}$, K.A. Gray ${ }^{\mathrm{a}^{*}}$

\section{*corresponding author}

aNorthwestern University, 2145 Sheridan Road, Evanston, IL 60208, USA (kgray@northwestern.edu)

bNIBEC, Ulster University, Newtownabbey, BT37 0QB, UK (j.byrne@ulster.ac.uk)

${ }^{\mathrm{c} T y n d a l l ~ N a t i o n a l ~ I n s t i t u t e, ~ U n i v e r s i t y ~ C o l l e g e ~ C o r k, ~ L e e ~ M a l t i n g s, ~ C o r k, ~ I r e l a n d ~}$ (michael.nolan@tyndall.ie) ${ }^{1}$ Present address: School of Chemistry, Trinity College Dublin, Dublin 2, Ireland

\section{Abstract}

The photochemical fixation of $\mathrm{CO}_{2}$ to energy rich products for solar energy storage or feedstock chemicals is an attractive, albeit daunting, challenge. The overall feasibility of $\mathrm{CO}_{2}$ conversion is limited by the availability of efficient photo-active materials that meet the energetic requirements for $\mathrm{CO}_{2}$ reduction and are optically matched to the solar spectrum. Surface modification of $\mathrm{TiO}_{2}$ with earth abundant metal oxides presents one approach to develop visible active photocatalysts through band gap narrowing, while providing catalytic sites to lower the activation energy for $\mathrm{CO}_{2}$ reduction. In this work density functional theory was used to model the effect of surface modification of rutile and anatase using $\mathrm{MnO}_{\mathrm{x}}$ nanoclusters. The results indicate the formation of inter-band gap states following surface modification with $\mathrm{MnO}_{x}$, but surface water can change this. Oxygen vacancies are predicted to form in supported $\mathrm{MnO}_{\mathrm{x}}$ and the interaction with $\mathrm{CO}_{2}$ was investigated. $\mathrm{MnO}_{\mathrm{x}}-\mathrm{TiO}_{2}$ was synthesised and characterised using surface analytical methods and photoelectrochemistry. The interaction of $\mathrm{CO}_{2}$ with the materials under irradiation was probed using in-situ FTIR to interrogate the role of oxygen vacancies in $\mathrm{CO}_{2}$ binding and reaction. These results provide insights into the requirements of a multifunctional catalyst for $\mathrm{CO}_{2}$ conversion.

Keywords: Photocatalysis, carbon dioxide, photoelectrochemistry, density functional theory, oxygen vacancies 


\section{Introduction}

The photochemical fixation of $\mathrm{CO}_{2}$ to energy rich products is an attractive, albeit daunting, challenge that attracts a great deal of recent interest [1-8]. The reduction of $\mathrm{CO}_{2}$ has a steep uphill thermodynamic barrier and the overall feasibility of $\mathrm{CO}_{2}$ conversion is limited by the availability of efficient photo-active materials that can meet the energetic requirements, while also being optically matched to the solar spectrum [9].

There are many reports of the heterogeneous photocatalytic reduction of $\mathrm{CO}_{2}$ on oxide semiconductors, particularly $\mathrm{TiO}_{2} . \mathrm{CO}_{2}$ reduction is observed, but reaction efficiencies are very low. The conversion of $\mathrm{CO}_{2}$ by photoactive oxides to energy-rich products is a complex system of reactions requiring novel, multifunctional nanoarchitectures that can harvest visible light, stabilize charge separation, activate $\mathrm{CO}_{2}$, and control the reaction pathway.

Figure 1 provides a sketch of a potential catalytic cycle for the reduction of $\mathrm{CO}_{2}$. Small domains of reducible oxides (for $\mathrm{MnO}_{\mathrm{x}}$, but this is extendable to other earth-abundant oxides) are synthesized on supports of appropriate or modified band gap for light harvesting (shown here as $\mathrm{TiO}_{2}$ ). $\mathrm{MnO}_{x}$ clusters are examined because they may create band gap states that red-shift $\mathrm{TiO}_{2}$ for visible light activation - Mn doping was presented in ref [10] and showed that Mn can create in-gap states - and broaden the valence band to favor charge injection (photocatalysis). Reduced metal centers and oxygen deficiencies are created thermally on $\mathrm{MnO}_{\mathrm{x}}$ clusters and are sites of $\mathrm{CO}_{2}$ adsorption and activation (Rx. 1, thermal catalysis). A photochemically generated electron ( $\mathrm{Rx} .2$ ) is transferred to $\mathrm{MnO}_{\mathrm{x}}$ and donated to the carboxylate (a specific form of adsorbed $\mathrm{CO}_{2}$ ) to achieve a 2-eletron reduction of $\mathrm{CO}_{2}$, cleaving the $\mathrm{C}-\mathrm{O}$ bond to produce $\mathrm{CO}$ and heal the oxygen vacancy. Water oxidation at the oxidized MnOx (Rx. 3), possibly photo- and thermo-driven, regenerates the active Ovacancy sites by the reverse of the classic Mars-van Krevelen mechanism and injects electrons to the $\mathrm{TiO}_{2}$ hole (Rx. 4). Crucially, reoxidation of surface vacancies with $\mathrm{O}_{2}$, which would short-cut the catalytic cycle, is avoided by maintaining very low $\mathrm{pO}_{2}$. Overall, then, the proposed multi-functional system combines both thermochemical and photochemical cycles for $\mathrm{CO}_{2}$ reduction and water oxidation.

The purpose of this paper is to probe the efficacy of this model theoretically and experimentally. Using first principles simulations, the effects of supporting $\mathrm{MnO}_{\mathrm{x}}$ clusters on various crystal facets of either anatase or rutile $\mathrm{TiO}_{2}$ [11-13] are explored to determine the extent of band-gap narrowing, the ease of forming oxygen vacancies and the mode of $\mathrm{CO}_{2}$ 
surface binding. To validate the theoretical findings experimentally, we compare the influence of synthesis conditions (precursor, support, loading) on light absorption, catalyst reduction and $\mathrm{CO}_{2}$ activation. The integration of theoretical and experimental findings yields deep insight into the structure and function of this $\mathrm{TiO}_{2}$-based nanocomposite and indicates the critical features of a multifunctional photo/thermal catalyst tailored for $\mathrm{CO}_{2}$ reduction.

\section{Methodology}

\subsection{Computational modelling}

To model the $\mathrm{MnO}_{\mathrm{x}}$-modified $\mathrm{TiO}_{2}$ rutile (110) and anatase (101) surfaces, we use a three dimensional periodic slab model within the VASP code [14]; full details of the methodology are given in the supporting information. The cut-off for the kinetic energy is $396 \mathrm{eV}$ and the core-valence interaction is described by PAW potentials [15]. The Perdew-Wang 91 exchange-correlation functional [16] and a Monkhorst-Pack $(2 \times 1 \times 1) \mathrm{k}$-point sampling grid and smearing width of $0.1 \mathrm{eV}$ are used. To describe the Ti $3 d$ and Mn $3 d$ states DFT+U [1719] is used where $U=4.5 \mathrm{eV}$ for both cations. This value of $U$ is sufficiently large to described localised $\mathrm{Ti}^{3+}[20-22]$ and $\mathrm{Mn}$ oxidation states and this set-up has been shown to be reliable $[12,20]$.

The rutile (110) and anatase (101) surfaces have two-fold coordinated bridging $O$ atoms terminating the surface layer and 5-fold/6-fold coordinated surface Ti atoms. For both surfaces (2x4) surface supercell expansions, 6 O-Ti-O trilayers thick are employed with a 12 $\AA$ vacuum gap. We employ stoichiometric surfaces (no defects and no adsorbed hydroxyls) and surfaces with different water coverages [13] (adsorption energies are computed similarly to Eq (1)) to examine the effect of a wet substrate on nanocluster absorption and the energy gap change.

The convergence criteria for the electronic and ionic relaxations are $0.0001 \mathrm{eV}$ and forces smaller than $0.02 \mathrm{eV} / \AA$. The $\mathrm{Mn}_{2} \mathrm{O}_{3}$ nanoclusters are less than $1 \mathrm{~nm}$ diameter and based on our previous work [12,21-24] can shift the absorption edge of $\mathrm{TiO}_{2}$ into the visible. The adsorption energy of the nanoclusters is computed from:

$E^{\text {ads }}=\mathrm{E}\left(\left(\mathrm{Mn}_{2} \mathrm{O}_{3}\right)-\mathrm{TiO}_{2}\right)-\left\{\mathrm{E}\left(\mathrm{Mn}_{2} \mathrm{O}_{3}\right)+\mathrm{E}\left(\mathrm{TiO}_{2}\right)\right\}$

where $\mathrm{E}\left(\left(\mathrm{Mn}_{2} \mathrm{O}_{3}\right)-\mathrm{TiO}_{2}\right)$ is the energy of an $\mathrm{Mn}_{2} \mathrm{O}_{3}$ stoichiometry nanocluster supported on a $\mathrm{TiO}_{2}$ surface and $\mathrm{E}\left(\mathrm{Mn}_{2} \mathrm{O}_{3}\right)$ and $\mathrm{E}\left(\mathrm{TiO}_{2}\right)$ are the total energies of the free $\mathrm{Mn}_{2} \mathrm{O}_{3}$ stoichiometry nanocluster and unmodified $\mathrm{TiO}_{2}$. A negative adsorption energy indicates that cluster adsorption is stable. 
The formation of oxygen vacancies is examined, using the formation energy to assess vacancy stability. After removing different oxygen atoms the vacancy formation energy is calculated from:

$E^{\mathrm{vac}}=\left\{\mathrm{E}\left(\mathrm{Mn}_{2} \mathrm{O}_{3-\mathrm{x}}-\mathrm{TiO}_{2}\right)+1 / 2 \mathrm{E}\left(\mathrm{O}_{2}\right)\right\}-\mathrm{E}\left(\mathrm{Mn}_{2} \mathrm{O}_{3}-\mathrm{TiO}_{2}\right)$

where $\mathrm{E}\left(\mathrm{Mn}_{2} \mathrm{O}_{3-\mathrm{x}}-\mathrm{TiO}_{2}\right)$ is the energy of modified $\mathrm{TiO}_{2}$ with an oxygen vacancy in the $\mathrm{Mn}_{2} \mathrm{O}_{3}$ nanocluster, $1 / 2 \mathrm{E}\left(\mathrm{O}_{2}\right)$ is the energy of oxygen and $\mathrm{E}\left(\mathrm{Mn}_{2} \mathrm{O}_{3}-\mathrm{TiO}_{2}\right)$ is the energy of the stoichiometric composite system. Bader charges and spin magnetisations characterise cation oxidation states.

\subsection{Catalyst preparation}

$\mathrm{MnO}_{x}-\mathrm{TiO}_{2}$ catalysts were prepared by incipient wetness impregnation. Nanopowders of rutile (Aldrich, 99.5\% trace metals basis) or anatase (Aldrich, 99.7\% trace metals basis) were calcined in air at $250^{\circ} \mathrm{C}$ for 2 hours, ground, and sieved. The titania supports were impregnated with a solution of either $\mathrm{Mn}\left(\mathrm{NO}_{3}\right)_{2} \cdot 4 \mathrm{H}_{2} \mathrm{O}$ (Sigma Aldrich 97.0\%) or $\mathrm{Mn}\left(\mathrm{CH}_{3} \mathrm{COO}\right)_{2} \cdot 4 \mathrm{H}_{2} \mathrm{O}$ (Sigma-Aldrich 99.0\%) in ultra-pure water in an agate mortar under constant stirring. The concentration of manganese precursor was varied to achieve surface loadings between 0.25 to $8 \mathrm{Mn}$ atoms per $\mathrm{nm}^{2}$ of support surface area. The impregnated supports dried overnight in ambient air, then at $120^{\circ} \mathrm{C}$ for 12 hours. These catalysts are referred to by describing the nominal $\mathrm{Mn}$ loading $\left(\mathrm{Mn} \mathrm{nm}^{-2}\right)$, the support material ( $\mathrm{A}$ or $\mathrm{R}$ ), and precursor anion (nitrate or acetate). For example, an anatase support loaded with $8 \mathrm{Mn}$ $\mathrm{nm}^{-2}$ from the $\mathrm{Mn}\left(\mathrm{NO}_{3}\right)_{2} \cdot 4 \mathrm{H}_{2} \mathrm{O}$ precursor is labelled 8ANO3 and rutile support loaded with 1 $\mathrm{Mn} \mathrm{nm}{ }^{-2}$ from the $\mathrm{Mn}\left(\mathrm{CH}_{3} \mathrm{COO}\right)_{2} \cdot 4 \mathrm{H}_{2} \mathrm{O}$ precursor is labelled $1 \mathrm{ROAc}$. The as-prepared $\mathrm{MnO}_{\mathrm{x}^{-}}$ $\mathrm{TiO}_{2}$ catalysts were calcined in air at $500^{\circ} \mathrm{C}$ for $4 \mathrm{~h}$.

\subsection{Catalyst Characterisation}

The optical absorption properties of the materials were measured with diffuse reflectance UV-vis spectroscopy (DRUV-vis) using a Shimadzu UV-3600 spectrophotometer equipped with a Harrick Praying Mantis diffuse reflectance holder. Powdered polytetrafluoroethylene (Aldrich, $35 \mu \mathrm{m}$ particle size) was the reflectance standard. Pseudo-absorption spectra were obtained by transforming the raw reflectance spectra using the Kubelka-Munk function. Band gap energies were estimated by linear fitting of Tauc plots[25].

The reducibility of the $\mathrm{MnO}_{x}-\mathrm{TiO}_{2}$ composites was assessed by temperature programmed reduction (TPR) using a T.A. Instruments Q500 Thermogravimetric Analyzer. Samples of the $\mathrm{MnO}_{\mathrm{x}}-\mathrm{TiO}_{2}$ composites calcined at $500^{\circ} \mathrm{C}$ for 4 hours were loaded into the TGA instrument 
and subjected to temperature programmed oxidation up to $500^{\circ} \mathrm{C}\left(10^{\circ} \mathrm{C} \mathrm{min}-1,10 \mathrm{~mL} \mathrm{~min}{ }^{-1}\right.$ $\mathrm{O}_{2}$ flow), were cooled to ambient temperature under $10 \mathrm{~mL} \mathrm{~min}^{-1} \mathrm{He}$, and were then subjected to another temperature ramp to $500^{\circ} \mathrm{C}\left(5^{\circ} \mathrm{C} \mathrm{min}{ }^{-1}, 10 \mathrm{~mL} \mathrm{~min}^{-1}\right.$ of a mixture of $5 \%$ $\mathrm{H}_{2}, 5 \% \mathrm{Ar}$, and balance He). Mass loss was measured by the TGA instrument.

In situ FTIR spectra were collected using a Nicolet 6700 (Thermo Scientific) IR spectrometer and a mercury cadmium telluride detector. Each spectrum was obtained by taking an average of 256 scans collected at $4 \mathrm{~cm}^{-1}$ resolution using a custom fabricated IR cell and sample preparation protocol previously described [26-29].

The samples were loaded into the cell, evacuated and heated at $5^{\circ} \mathrm{C} / \mathrm{min}$ to $350^{\circ} \mathrm{C}$, held at that temperature under vacuum for $15 \mathrm{~min}$, then 30 torr of ultra-high purity $\mathrm{O}_{2}(99.999 \%)$ was admitted to the cell. After 15 min the cell was evacuated, then 30 Torr of ultra-high purity $\mathrm{H}_{2}$ (99.999\%) was admitted. The materials were reduced in this atmosphere for a further 15 minutes, then the heating element was turned off and the materials were allowed to cool to ambient temperature before being evacuated again. Background spectra were recorded before introducing 30 Torr of ultra-high purity $\mathrm{CO}_{2}(99.999 \%)$ and sealing the cell. Difference spectra were recorded after 30 min of adsorption time.

\subsection{Photoelectrochemical Characterisation}

The powder samples were suspended in anhydrous methanol (Sigma Aldrich) to give a 5\% by weight suspension and sonicated. Films were spray coated on titanium foil $\left(20 \times 25 \mathrm{~mm}^{2}\right)$ using a lab spray gun (Badger Model 250-2) to give a coated area of $20 \times 20 \mathrm{~mm}^{2}$ with a catalyst loading of $1 \mathrm{mg} \mathrm{cm}^{-2}$. The samples were annealed in air at $400^{\circ} \mathrm{C}$ (ramp $2^{\circ} \mathrm{C}$ up, $1^{\circ} \mathrm{C} / \mathrm{min}$ down). Electrical connection was made to the foil using copper wire and conductive silver epoxy (circuit works CW2400). Any area of the electrode not coated with catalyst was insulated with SU8 photoresist (Microchem) leaving an area of $20 \times 20 \mathrm{~mm}^{2}$ of catalyst exposed.

Electrochemical measurements were performed with a three electrode cell modified with a quartz window. The supporting electrolyte was $0.1 \mathrm{M} \mathrm{NaHCO}_{3}$. The counter electrode was a Pt gauze electrode and the reference electrode was a saturated calomel electrode (SCE). Potentiostatic control was implemented using an Autolab PG30 Stat and irradiation was provided by a $450 \mathrm{~W}$ xenon lamp with or without and a $435 \mathrm{~nm}$ cut off filter or monochromator (Horiba Jobin Yvonne Gemini 120). A chopper (Uniblitz) was used for chopped irradiation. All potentials are reported vs SCE. 


\subsection{Results and discussion}

\subsection{DFT Modelling of $\mathrm{Mn}_{2} \mathrm{O}_{3}$-nanocluster modified rutile and anatase $\mathrm{TiO}_{2}$}

\subsection{1 $\mathrm{Mn}_{2} \mathrm{O}_{3}$ Nanocluster Adsorption at $\mathrm{TiO}_{2}$ Surfaces}

Figure 2 shows the atomic structure of dry rutile (110) and anatase (101) modified with an $\mathrm{Mn}_{4} \mathrm{O}_{6}$ nanocluster and with water coverages of 1 monolayer (ML) for rutile and $3 / 4 \mathrm{ML}$ for anatase; the supporting information (figures S1 and S2) shows the atomic structure of the dry and water covered $\mathrm{TiO}_{2}$ surfaces modified with $\mathrm{Mn}_{4} \mathrm{O}_{6}$ and $\mathrm{Mn}_{6} \mathrm{O}_{9}$ nanoclusters. Water is stable at different coverages on rutile and anatase (see SI) [13].

The relaxed atomic structures of the $\mathrm{Mn}_{4} \mathrm{O}_{6}$ nanocluster adsorbed at dry $\mathrm{TiO}_{2}$ and with 1 monolayer (ML) and $3 / 4 \mathrm{ML}$ water coverage on rutile (110) and anatase (101), respectively, are shown in Figure 2. The adsorption energies of $\mathrm{Mn}_{4} \mathrm{O}_{6}$ are $-7.20 \mathrm{eV}$ and $-5.33 \mathrm{eV}$ on dry rutile and anatase and $-1.69 \mathrm{eV}$ and $-4.94 \mathrm{eV}$ and rutile and anatase with water; the adsorption energy of $\mathrm{Mn}_{6} \mathrm{O}_{9}$ on dry rutile is $-6.02 \mathrm{eV}$. In general (see $\mathrm{SI}$ ) strong $\mathrm{Mn}_{4} \mathrm{O}_{6}$ nanocluster adsorption energies persist on water covered surfaces; although the rutile (110) surface with $1 \mathrm{ML}$ water has a smaller adsorption energy, this is still reasonable.

After relaxation on water covered $\mathrm{TiO}_{2}$, hydrogen migrates from surface water, forming new bonds to nanocluster oxygen, passivating oxygen and forming hydroxyls. On rutile, as the water coverage increases, more hydrogen atoms migrate to the nanocluster (figure S2), passivating more oxygen species. On anatase there is less hydrogen migration from adsorbed water to the nanocluster. This is consistent with the more negative adsorption energies of $\mathrm{Mn}_{4} \mathrm{O}_{6}$ at anatase compared to rutile.

Figure 2 shows the projected electronic density of states (PEDOS) for $\mathrm{Mn}_{4} \mathrm{O}_{6}$ modified dry and wet rutile (110) and anatase (101). On the dry $\mathrm{TiO}_{2}$ surfaces, new states, originating from the nanocluster, are found in the valence to conduction band energy gap of $\mathrm{TiO}_{2}$. We predict a strong red shift of light absorption resulting from the reduced energy gap between the highest occupied and lowest unoccupied electronic states of the composite system.

The PEDOS for $\mathrm{Mn}_{4} \mathrm{O}_{6}$ modified water covered $\mathrm{TiO}_{2}$ shows that for modified rutile(110), the key effect of water is an apparent reduction in the electronic states in the $\mathrm{TiO}_{2}$ energy gap which have almost disappeared at $1 \mathrm{ML}$ water coverage (Figure 2, Figure S3). Surface water appears to prevent strong nanocluster-surface interactions needed to modify the rutile $\mathrm{TiO}_{2}$ energy gap. Passivating nanocluster oxygen by hydrogen can also remove nanocluster 
derived states from the energy gap, ultimately giving no red shift. For modified anatase with water, the reduced hydrogen migration and strong nanocluster-surface interaction means that the $\mathrm{Mn}_{4} \mathrm{O}_{6}$ derived states persist in the $\mathrm{TiO}_{2}$ energy gap so that modification of anatase with $\mathrm{Mn}_{4} \mathrm{O}_{6}$ gives a red shift. Given the nature of the valence and conduction band edges, we suggest an interfacial charge transfer process [30] from supported $\mathrm{Mn}_{2} \mathrm{O}_{3}$ to $\mathrm{TiO}_{2}$; a similar process has been described in our earlier work, refs [11-13].

We studied oxygen vacancies in $\mathrm{Mn}_{4} \mathrm{O}_{6}$-modified rutile and anatase (with no surface water). Figure 3 (a), (b) shows the structure of the most stable oxygen vacancy site in $\mathrm{Mn}_{4} \mathrm{O}_{6}$ modified rutile (110) and anatase (101). Formation energies are $+0.59 \mathrm{eV}$ and $+1.1 \mathrm{eV}$ on rutile and anatase. The vacancy originates in $\mathrm{Mn}_{4} \mathrm{O}_{6}$, consistent with our earlier work on surface modified $\mathrm{TiO}_{2}$ [31]. There is a low cost to form the $\mathrm{O}$ vacancy in the composite, compared to ca. $3.5 \mathrm{eV}$ on bare rutile and anatase. On $\mathrm{Mn}_{4} \mathrm{O}_{6}$-rutile (110), the two electrons reduce two $\mathrm{Mn}^{3+}$ sites to $\mathrm{Mn}^{2+}$. On $\mathrm{Mn}_{4} \mathrm{O}_{6}$-anatase (101), one electron reduces an $\mathrm{Mn}^{3+}$ site to $\mathrm{Mn}^{2+}$ and the second electron reduces a surface $\mathrm{Ti}$ atom in anatase.

We examined the interaction of $\mathrm{CO}_{2}$ with the defective structures to investigate if the oxygen vacancy and the reduced metal sites can participate in $\mathrm{CO}_{2}$ activation. Figure 3 (c) - (e) show relaxed adsorption modes for $\mathrm{CO}_{2}$ at defective $\mathrm{Mn}_{4} \mathrm{O}_{6}$-rutile (110). We identify noninteracting (Figure 3 (c)), bidentate (two $\mathrm{Mn}-\mathrm{O}$ bonds between the nanocluster and $\mathrm{CO}_{2}$ ), Figure $3(\mathrm{~d})$, and bidentate carbonate (Figure $3(\mathrm{e})$ ); the computed adsorption energies are $0.21 \mathrm{eV},-0.55 \mathrm{eV}$ and $+0.68 \mathrm{eV}$; the carbonate-like adsorption mode is not stable. Similar $\mathrm{CO}_{2}$ adsorption energies are found at other nanocluster-modified $\mathrm{TiO}_{2}$ composites [32]. In the bidentate adsorption mode, the $\mathrm{C}$-O distances in $\mathrm{CO}_{2}$ are elongated to 1.24 and $1.26 \AA$ and the molecule has a bent structure.

Figure 3 (e) shows the relaxed adsorption structure of $\mathrm{CO}_{2}$ at defective $\mathrm{Mn}_{4} \mathrm{O}_{6}$-anatase in which a $\mathrm{C}-\mathrm{O}$ bond in $\mathrm{CO}_{2}$ breaks and $\mathrm{CO}$ is released, with a small energy gain of $0.37 \mathrm{eV}$, and the vacancy is healed.

\subsection{Catalyst characterisation}

Normalized Kubelka-Munk pseudo-absorbance spectra for the $\mathrm{MnO}_{\mathrm{x}}-\mathrm{TiO}_{2}$ (anatase) composites are presented in Figure 4. Anatase supported materials showed a red shift in the absorbance edge relative to the bare anatase support, which arises from the modification of $\mathrm{TiO}_{2}$. They also show broad absorbance in the visible light range, which increases with $\mathrm{Mn}$ loading (due to transitions within supported $\mathrm{MnO}_{\mathrm{x}}$ ). The rutile-supported materials showed a small extension of absorbance into the visible light range (Figure S5), but to a much lesser extent than for anatase supported materials. 
Band gap energies of the composites and the bare supports were calculated by linear fitting of Tauc plots and are shown in Table S1. The anatase-supported materials with $0.25 \mathrm{Mn} \mathrm{nm}^{-}$ 2 loading show a negligible shift in band gap relative to the $3.15 \mathrm{eV}$ band gap of bare anatase, but a significant trend of decreasing band gap is evident at higher loadings with the highest $\mathrm{Mn}$ loading materials showing a band gap of $2.74 \mathrm{eV}$ (8ANO3) and $2.30 \mathrm{eV}$ (BAOAc). The red shift is greater in the AOAc materials than the ANO3 materials at all Mn loadings and the differences grow with increasing $\mathrm{Mn}$ loading. For all of the $\mathrm{MnO}_{\mathrm{x}}-\mathrm{TiO}_{2}$ rutile composites there is no marked change in the band gap energy at any Mn loading. These results point to the influence of both support and precursor on the structure and optoelectronic properties of $\mathrm{MnO}_{x}-\mathrm{TiO}_{2}$ materials.

The photoresponse of the anatase-supported materials is consistent with computational results for small clusters of $\mathrm{Mn}_{2} \mathrm{O}_{3}$ composition on anatase (101) that predict the introduction of states above the valence band of anatase, resulting in decreased band gap energy. As shown computationally, the presence of water on the surface of rutile can change the effect of the nanocluster modifier and result in no significant change to the energy gap, as observed experimentally.

There are potential differences between computation and experimental results. The computational results are obtained for very small ( $<1 \mathrm{~nm}$ diameter) clusters of $\mathrm{Mn}_{2} \mathrm{O}_{3}$, however the size of the $\mathrm{MnO}_{\mathrm{x}}$ domains in the $\mathrm{MnO}_{\mathrm{x}}-\mathrm{TiO}_{2}$ composites synthesized for this study is likely much larger, especially at higher Mn loadings. Also, the computations were focused on idealised crystal surfaces, whereas the surfaces of the support materials used in the experiments contain defects and can have additional exposed facets beyond anatase (101) and rutile (110). Furthermore, the Mn precursor and the nature of the titania support material may influence the final composite structures in ways that cannot not be captured by computational modelling. Nevertheless, the qualitative agreement for the red shift on modified anatase (with or without water present on the anatase surface) and the effect of water on the energy gap change for rutile is reasonable.

TPR curves for the $\mathrm{MnO}_{\mathrm{x}}-\mathrm{TiO}_{2}$ composites are shown in Figure 5. The plots show the negative first derivative of catalyst mass with respect to temperature. Peaks correspond to mass loss associated with reduction of the catalyst and generation of oxygen vacancies. The curves for the $\mathrm{MnO}_{\mathrm{x}}-\mathrm{TiO}_{2}$ composites show two main features. The first is a low temperature feature centered between $150-300^{\circ} \mathrm{C}$. This peak is also present in the bare anatase and rutile curves and represents the reduction of the titania to generate oxygen vacancies and accompanying $\mathrm{Ti}^{3+}$ sites. The feature is supressed in low loading composites, but reappears at higher loadings and trends towards lower temperature with increased Mn loading. The 
second feature is a broad peak between $250-500^{\circ} \mathrm{C}$ that becomes larger in area and devolves into two or more distinct peaks with increasing Mn loading. This feature is not present in the bare support materials and is likely a result of the generation of oxygen vacancies in the $\mathrm{MnO}_{\mathrm{x}}$ domains. At lower $\mathrm{Mn}$ loadings, the broad feature indicates multiple populations of oxygen vacancies over that range. As the Mn loading increases, especially on the anatase supported materials, two distinct peaks appear, a result that is consistent with the presence of bulk-like $\mathrm{MnO}_{2}$ domains undergoing a two-step reduction. This behaviour is more pronounced on the anatase supported materials, especially $\mathrm{ANO}_{3}$, than on rutile.

These results indicate that the $\mathrm{MnO}_{x}-\mathrm{TiO}_{2}$ materials are reduced to form oxygen vacancies, including some at relatively mild temperatures, as predicted in the DFT calculations. The reducibility of the materials increases with $\mathrm{Mn}$ loading and appears to be greater for anatasethan for rutile-supported materials. The data also show the appearance of features associated with bulk-like $\mathrm{MnO}_{2}$, especially at higher $\mathrm{Mn}$ loading. This underlines one possible limitation in comparing the computational results and experimental work - the size of supported $\mathrm{MnO}_{\mathrm{x}}$ clusters generated experimentally is likely much larger than what can be modelled, accounting for differences with DFT results that suggest reducibility is not strongly affected by the support.

\subsection{Photoelectrochemical characterisation}

To investigate the effective band gap, photocurrent measurements were performed under UV-vis and visible only irradiation. The onset potential for anodic current shifted positive with increased $\mathrm{MnO}_{x}$ loading. Samples with the highest $\mathrm{MnO}_{x}$ loading showed an oxidation peak around $+0.25 \mathrm{~V}$, which correlates to previous reports relating to $\mathrm{Mn}^{2+}$ oxidation [33]. Under UV-Vis irradiation the $\mathrm{MnO}_{\mathrm{x}}$ modification gave a lower photocurrent as compared to unmodified $\mathrm{TiO}_{2}$. Linear sweep voltammograms (LSVs) for anatase and 0.25AOAc $\mathrm{MnO}_{x^{-}}$ $\mathrm{TiO}_{2}$ are shown in Figure S6. Photocurrent was difficult to determine at higher Mn loadings due to increased dark current. Under visible only irradiation, very small photocurrents were observed with the anatase and $0.25 \mathrm{ANO} 3 \mathrm{MnO}_{\mathrm{x}}-\mathrm{TiO}_{2}$ samples (Figure S7). A more noticeable photocurrent was observed with higher loadings of $\mathrm{MnO}_{\mathrm{x}}$; however, the observed photocurrents under visible irradiation were only a fraction of the photocurrent observed under UV-Vis irradiation. To further investigate any red shift in absorption the spectral photocurrent response at fixed potential was determined using monochromatic irradiation. The spectral response for the anatase and 0.25ANO3 samples is shown in Figure 6. The anatase sample shows a typical response with maximum photocurrent in the UV. The anatase sample also shows a small visible response due to defect sites. The $\mathrm{MnO}_{\mathrm{x}}-\mathrm{TiO}_{2}$ has a relatively lower UV response and no real improvement in the visible photocurrent 
response is observed. These results correlate with previous spectral photocurrent measurements on $\mathrm{N}, \mathrm{F}-\mathrm{TiO}_{2}$ samples, where a red shift in the optical absorption spectrum was observed, however, no real shift in the photocurrent spectrum was observed [34].

The change in the open circuit potential $\left(E_{\mathrm{OC}}\right)$ under polychromatic UV-Vis and visible only irradiation is shown in Figure $\mathrm{S} 8$ for the anatase and $0.25 \mathrm{ANO} 3 \mathrm{MnO}_{\mathrm{x}}-\mathrm{TiO}_{2}$. The $E_{\mathrm{OC}}$ shifts negative from ca $+750 \mathrm{mV}$ (dark) to $-300 \mathrm{mV}$ under UV-Vis irradiation while the $E_{\mathrm{OC}} \mathrm{MnO}_{\mathrm{x}^{-}}$ $\mathrm{TiO}_{2}$ also shifts negative, but not as much as the anatase sample. Under visible only irradiation, the negative shift in the $E_{\mathrm{OC}}$ is more pronounced for the $\mathrm{MnO}_{\mathrm{x}}-\mathrm{TiO}_{2}$ sample as compared to anatase. Although the photocurrent under visible irradiation is similar for both samples, the negative shift in $\mathrm{E}_{\mathrm{OC}}$ is more pronounced for the $\mathrm{MnO}_{\mathrm{x}}-\mathrm{TiO}_{2}$ as compared to the anatase, indicating that visible light excitation of the $\mathrm{MnO}_{x}-\mathrm{TiO}_{2}$ gives a negative shift in the Fermi energy level of the material but photogenerated electrons cannot be collected as photocurrent, probably due to rapid recombination at defect sites.

Figure 7 shows the open circuit photopential ( $E_{\mathrm{OCP}}$, the potential under irradiation minus the dark equilibrium potential) as a function of wavelength for monochromatic irradiation. It is observed that as the $\mathrm{MnO}_{\mathrm{x}}$ loading increases the negative shift in the $E_{\mathrm{OCP}}$ under UV irradiation becomes less while the visible $E_{\mathrm{OCP}}$ shifts more negative. This agrees to previous findings where it was observed that the $E_{O C P}$ gives a better correlation to the optical absorption spectra for the materials as compared to the photocurrent spectra [34].

Although the $E_{\mathrm{OCP}}$ shifts are always negative, the actual measured $E_{\mathrm{OC}}$ becomes more positive with increasing $\mathrm{MnO}_{\mathrm{x}}$ loading. This indicates a positive shift in the $E_{\mathrm{OC}}$ probably being determined by the redox potential of the $\mathrm{Mn}^{4+} / \mathrm{Mn}^{2+}$ couple.

\section{$3.4 \mathrm{CO}_{2}$ binding under UV irradiation}

In contrast to theoretical findings, we did not detect $\mathrm{CO}_{2}$ conversion to $\mathrm{CO}$ or any other product on any of the synthesized $\mathrm{MnO}_{x}-\mathrm{TiO}_{2}$ composites. In order to explain these results, we evaluated $\mathrm{CO}_{2}$ binding at the material surface with FTIR. The spectra in Figure S9 reveal that the $0.25 \mathrm{ANO} 3$ material shows greater relative intensity of the peak (at $1247 \mathrm{~cm}^{-1}$ ) associated with carboxylate species than does the bare anatase support. In contrast, the $0.25 \mathrm{AOAc}$ spectrum is almost identical to that of anatase. Compared to anatase, the highly Mn-loaded 8ANO3 and 8AOAc spectra show relatively greater intensity for peaks associated with bidentate carbonates $\left(1281,1324,1555 \mathrm{~cm}^{-1}\right)$ and bicarbonates $\left(1222,1398,1418 \mathrm{~cm}^{-}\right.$

$\left.{ }^{1}\right)[28,29,35-38]$ and relatively lower intensity for peaks associated with carboxylates (1247, $\left.1670 \mathrm{~cm}^{-1}\right)$. Spectra for rutile supported composites show a similar trend of increased 
relative intensity of features associated with monodentate and bidentate carbonates as well as bicarbonates.

The FTIR spectra (Figure S9) present evidence of $\mathrm{CO}_{2}$ binding in a variety of configurations, including carboxylate and bidentate carbonate, which are both associated with interactions between $\mathrm{CO}_{2}$ and oxygen vacancies and/or electron donation from associated $\mathrm{Ti}^{3+}$ sites $[28,29]$. Since the bare titania and $\mathrm{MnO}_{x}-\mathrm{TiO}_{2}$ composites were reduced during the pretreatment, it is likely that the same mechanism is at play here, with electron donation from a reduced $\mathrm{Ti}$ center in the case of anatase/rutile or a reduced Ti or Mn center in the case of the $\mathrm{MnO}_{\mathrm{x}}-\mathrm{TiO}_{2}$ composites. However, the spectra for the $\mathrm{MnO}_{\mathrm{x}}-\mathrm{TiO}_{2}$ composites show a greater proportion of the bound $\mathrm{CO}_{2}$ in the form of carbonates and bicarbonates, than carboxylates, which was observed on the bare titania. Carboxylates include the $\mathrm{CO}_{2}^{-}$moiety, which is believed to be an important intermediate in $\mathrm{CO}_{2}$ photoreduction [28,29,39-41] whereas carbonates and bicarbonates are relatively stable and may not yield $\mathrm{CO}_{2}$ reduction products. Therefore, while $\mathrm{CO}_{2}$ is observed to bind to $\mathrm{MnO}_{x}-\mathrm{TiO}_{2}$, it does not do so in the activated state that is advantageous for $\mathrm{CO}_{2}$ reduction.

\subsection{Concluding Remarks}

We propose a novel nanoarchitecture of $\mathrm{MnOx}$ clusters supported on $\mathrm{TiO}_{2}$ that cycles between $\mathrm{Mn}^{3+}$ and $\mathrm{Mn}^{2+}$ with an input of thermal and light energy using $\mathrm{CO}_{2}$ to produce $\mathrm{CO}$ and heal oxygen vacancies. DFT predicts that this composite shows band gap narrowing and visible light activity, facile formation of oxygen vacancies and reduced Mn-centers, and possible $\mathrm{CO}_{2}$ reduction to $\mathrm{CO}$. The presence of water on $\mathrm{TiO}_{2}$ may, however, unfavourably affect these interactions, particularly the red-shift after $\mathrm{MnO}_{\mathrm{x}}$ modification.

Experimental studies yield new insights into the structure and function of the multifunctional catalyst. Only $\mathrm{MnO}_{x}$ supported on anatase displayed a red-shift which increased with $\mathrm{MnO}_{x}$ loading. In contrast, photoelectrochemistry revealed that increased $\mathrm{MnO}_{\mathrm{x}}$ loading decreased total anodic photocurrent, with a minor enhancement in visible light current; this was attributed to electron trapping by $\mathrm{MnO}_{x}$ defects. Although these defects are detrimental to anodic current, they may be favourable for $\mathrm{CO}_{2}$ reaction. In agreement with theory, TPR shows that oxygen vacancies were easily formed, particularly on anatase supports. However, FTIR results indicate that $\mathrm{CO}_{2}$ adsorption does not occur in the preferred carboxylate configuration, failing to heal oxygen vacancies and produce $\mathrm{C}-\mathrm{O}$ cleavage. Oxygen vacancies on $\mathrm{MnO}_{x}$ clusters, with low formation energies, may be too stable for oxidation by $\mathrm{CO}_{2}$ and our ongoing efforts are focused on evaluating metal oxide clusters that produce more reactive defects. Finally, these results illustrate the value of integrating theory and experiments to understand the complex structure-function relationships required for the 
photoreduction of $\mathrm{CO}_{2}$. There is a clear influence of both the crystal form of $\mathrm{TiO}_{2}$ and the surface coverage of water on the red shift in the composite and on vacancy formation. These are important factors in the design of surface modified $\mathrm{TiO}_{2}$ photocatalysts.

\section{Acknowledgements}

The authors acknowledge support from the US-Ireland R\&D Partnership Program, NSF (CBET-1438721), SFI (SFI 14/US/E2915) and DELNI (USI065). MN acknowledges support from Science Foundation Ireland (SFI) through the Starting Investigator Research Grant Program, project "EMOIN", grant number SFI 09/SIRG/I1620 and the European Commission through the COST Action CM1104 “'Reducible Metal Oxides, Structure and Function". Researchers at Northwestern acknowledge the support of NSF. We acknowledge SFI funded computing resources at Tyndall and the SFI/HEA funded Irish Centre for High End Computing and the European Commission Partnership in Advanced Computing (contracts RI-261557, RI-283493 and RI-312763).

\section{References}

1. M. R. Hoffmann, J. A. Moss, M. M. Baum, Dalton Trans., 40 (2011) 5151-5158.

2. M. Aresta, A. Dibenedetto, Dalton Trans., 28 (2007) 2975-2992.

3. T. Sakakura, J.C. Choi, H. Yasuda, Chemical Reviews, 107(2007) 2365-2387.

4. S. N. Riduan, Y. Zhang, Dalton Trans., 39 (2010) 3347-3357.

5. S. Enthaler, J. von Langermann, T. Schmidt, Energy Environ. Sci., 3 (2010) 12071217.

6. R. W. Dorner, D. R. Hardy, F. W. Williams, H. D. Willauer, Energy Environ. Sci., 3 (2010) 884-890.

7. S. C. Roy, O. K. Varghese, M. Paulose, C. A. Grimes, ACS Nano, 4 (2010) 12591278.

8. K. C. Schwartzenberg, K. A. Gray, Catal. Sci. Technol., 2 (2012) 1617-1624.

9. US DoE, Basic Research Needs: Catalysis for Energy - Report from the U.S. Department of Energy Basic Energy Sciences Workshop, August 6-8 2007, 2007.

10. Z. V. Saponjic, N. M. Dimitrijevic, O. G. Poluektov, L. X. Chen, E. Wasinger, U. Welp, D. M. Tiede, , X. Zuo, T. Rajh, J. Phys. Chem. B, 110 (2006) 25441-25450.

11. M. Nolan, Chem. Comm., 47 (2011) 8617-8619.

12. H. Tada, Q. Jin, A. Iwaszuk, M. Nolan, J. Phys. Chem. C, 118 (2014) 12077-12086.

13. M. Fronzi, A. Iwaszuk, A. K. Lucid and M. Nolan, J. Phys.: Condens. Matter, 28 (2016) 074006 (23pp).

14. G. Kresse, J. Hafner, Phys. Rev. B 49 (1994) 14251 - 14269.

15. P. E. Blöchl, Phys. Rev. B, 50 (1994) 17953 - 17979.

16. J. P. Perdew, in Electronic Structure of Solids '91, eds. P. Ziesche, P; Eschrig, H. Akademie Verlag, Berlin, 1991.

17. V. I. Anisimov, J. Zaanen, O. K. Andersen, Phys. Rev. B, 44 (1991) 943-954.

18. S. L. Dudarev, G. A. Botton, S. Y. Savrasov, C. J. Humphreys, A. P. Sutton, Phys. Rev. B 57 (1998) 1505-1509.

19. B. J. Morgan, G. W. Watson, Surf. Sci., 601 (2007) 5034-5041. 
20. M. Fujishima, Q. Jin, H. Yamamoto, H. Tada, M. Nolan, Phys. Chem. Chem. Phys. 14 (2012) $705-711$

21. A. Iwaszuk, M. Nolan, Q. Jin, M. Fujishima, H. Tada, J. Phys. Chem. C, 117 (2013) 2709-2718.

22. Q. Jin, M. Fujishima, A. Iwaszuk, M. Nolan, H. Tada, J. Phys. Chem. C 117 (2013) $23848-23857$.

23. H. Tada, Q. Jin, H. Nishijima, H. Yamamoto, M. Fujishima, S.-I Okuoka, T. Hattori, Y. Sumida, H. Kobayashi, Angew Chem, 50 (2011) 3501 - 3505.

24. Q. Jin, M. Fujishima, H. Tada, J. Phys. Chem C, 115 (2011) $6478-6483$.

25. J. Tauc, R. Grigorovici, A. Vancu, Physica Status Solidi b, 15(1966) 627-637.

26. Y. H. Yeom, B. Wen, W. M. H. Sachtler, E. J. Weitz, Phys. Chem. B, 108 (2004) 5386-5392.

27. P. Basu, T. H. Ballinger, J. T. Yates, Rev. Sci. Instrum. 1988, 59, 1321-1327.

28. K. Bhattacharyya, A. Danon, B.K. Vijayan, K. A. Gray, P. C. Stair, E. J. Weitz, Phys. Chem. C 2013, 117, 12661-12678.

29. W. Wu, K. Bhattacharyya, K.A. Gray, E. J. Weitz, Phys. Chem. C, 117 (2013) 20643-20655.

30. M. Miyauchi, H. Irie, M. Liu, X. Qiu, H. Yu, K. Sunada, K. Hashimoto, J. Phys. Chem. Lett., 7 (2016) 75-84.

31. A. Iwaszuk, M. Nolan Phys. Chem. Chem. Phys, 13 (2011) 4963-4973.

32. M. Fronzi, W. Daly, M. Nolan, Appl. Cat. A, 28 (2016) 1-23.

33. Q. Jin, H. Arimoto, M. Fujishima, H. Tada, Catalysts, 3 (2013) 444-454.

34. J.W.J. Hamilton, J. A. Byrne, P.S.M. Dunlop, D. D. Dionysiou,M. Pelaez, K. O'Shea, D. Synnott, S. C. Pillai, J. Phys. Chem. C, 118 (2014) 12206-12215.

35. K. Bhattacharyya, W. Wu, E. Weitz, B. Vijayan, K. Gray, Molecules, 20 (2015) 1546915487.

36. G. Busca, V. Lorenzelli, Materials Chemistry, 7 (1982) 89-126.

37. S. E. Collins, M. A. Baltanás, A. L. Bonivardi, J. Phys. Chem. B 110 (2006) 54985507.

38. W. Su, J. Zhang, Z. Feng, T. Chen, P. Ying, C. Li, J. Phys. Chem. C, 112 (2008) 7710-7716.

39. C.C. Yang, Y.H Yu, B. van der Linden, J. C. S. Wu, G. Mul, J. Am. Chem. Soc. 132 (2010) 8398-8406.

40. J. Rasko, F. Solymosi, J. Phys. Chem., J. Phys. Chem., 98 (1994) 7147-7152.

41. J. Raskó, Catal. Lett., 56, (1998) 11-15. 